\title{
Some traffic characteristics of rural roads in Iraq
}

\author{
Hamid Athab Al-Jameel ${ }^{1, *}$, and Ali Jihad Kadhim ${ }^{2}$ \\ ${ }^{1}$ University of Kufa, Najaf, Iraq \\ ${ }^{2}$ Al-Mustansiriyah University, Baghdad, Iraq
}

\begin{abstract}
Now a days, modeling traffic characteristics are very important in evaluating traffic facilitates such normal section, weaving and merging sections. Lane changing and lane utilization are important traffic characteristics that are widely studied. Therefore this study is focused on both of these. The lane changing behavior affects the capacity and safety of roads. The distribution of vehicles among lanes of roadway is important in terms of different aspects such as safety, traffic management and even the structural design of roads. Field data have been collected from different rural roads. Two types of roads were studied; two-lane section and three-lane section. The results of analysis for collected data indicate that the driver behaviour is different in terms of lane utilization in Iraq from other countries and the same behaviour was found for lane changes also. Compared to other countries, Iraq has the lowest lane utilization and highest frequency of lane changes. These data are urgently needed nowadays for calibrating and validating the sophisticated programs such as simulated microscopic programs. These data are so important to mimic the reality for driver behaviors in rural roadways.
\end{abstract}

\section{Introduction}

Studying driver behavior is very important factor in modeling traffic stream [1]. Lot of studies have proved that field data could be used to model different driver behaviors such as car-following, lane changing, lane utilization and gap acceptance [2-4]. In Iraq, however, approximately no such field data have been collected for rural roads in terms of lane change and lane utilization. [5] has focused on studying the driver behavior for three lane normal section for both urban and suburban roads. Therefore, this study has been devoted to collect and analyze field data for rural roads.

\section{Lane changing behavior}

The lane changing (LC) behavior could be expressed as the desire of a driver to change the lane in order to avoid loss of his/her desired speed or to reach his/her destination. According to previous literatures, the LC could be classified as mandatory and discretionary. The first type is about when a driver tries to reach his/her destination; whereas the second type is how a driver avoids loss his desired speed because of slowing vehicles ahead $[3,5]$.

\section{Lane utilization behaviour}

Lane utilization (LU) represents how the vehicles are distributed among different lanes. [6] showed that the LU for the three lane normal section in the UK could be summarized as indicated in Figure 1. This figure demonstrates clearly that when the flow is low, most of the vehicles occupy the first lane and to some extent the second lane; whereas the third lane is almost free from vehicles excepting those vehicles who need to overtake.

Generally, as the flow increases from low to moderate, the usage of the third lane increases from approximately zero to approximately $50 \%$. On the other hand, the LU for both the first and second lane decreases until reach the minimum value of the capacity as indicated in Figure 1. This behavior could be interpreted by using the first lane widely at low flow and as flow increases the drivers try to avoid the reduction in their speed by shifting to the third lane until it reaches the capacity.

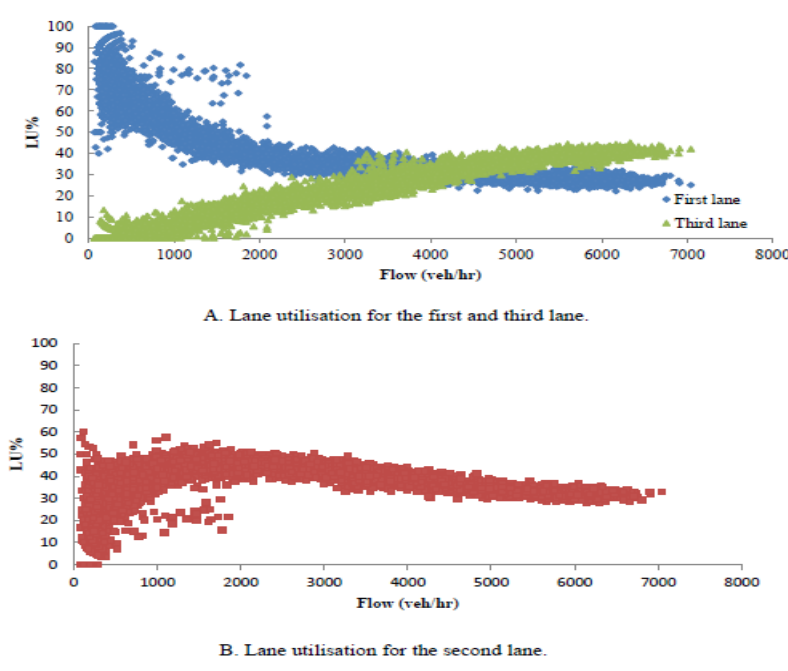

Fig. 1. LU for three lane normal section.

\footnotetext{
${ }^{*}$ Corresponding author: hamid.aljameel@uokufa.edu.iq
} 


\section{Data collection and analysis}

Different sites have been selected during this study. These sites are on different rural roads with two and three lanes in each direction. Table 1 indicates these sites with the duration of data collection. Two Sony video cameras have been used to capture the field data. The selection of a vantage point was one of the most challenging things in line with getting security permission that was faced during the data collection stage. Footbridges have been selected as the best vantage point to monitor the traffic stream.

Table 1. Different sites of data collection in Iraq.

\begin{tabular}{|c|c|c|c|}
\hline $\begin{array}{l}\text { Site } \\
\text { No. }\end{array}$ & Site name & Duration & Date \\
\hline 1 & The Expressway No.1/R4 & 5 hours & $22-9-2016$ \\
\hline \multirow{3}{*}{2} & \multirow{3}{*}{$\begin{array}{l}\text { R8 (Baghdad - Al- } \\
\text { Mahmoudiyah) }\end{array}$} & $\begin{array}{l}2 \text { hours and } 15 \\
\text { minutes }\end{array}$ & $\begin{array}{l}10-10- \\
2016\end{array}$ \\
\hline & & $\begin{array}{l}3 \text { hours and } 15 \\
\text { minutes }\end{array}$ & $\begin{array}{l}17-10- \\
2016\end{array}$ \\
\hline & & 3 hours & $\begin{array}{l}28-12- \\
2016\end{array}$ \\
\hline 3 & R6 (Baghdad - Al Kut). & $\begin{array}{l}1 \text { hours and } 30 \\
\text { minutes }\end{array}$ & $\begin{array}{l}27-10- \\
2016 \\
\end{array}$ \\
\hline 4 & R6 (Baghdad - Al Kut). & $\begin{array}{l}2 \text { hours and } 20 \\
\text { minutes }\end{array}$ & $\begin{array}{l}27-10- \\
2016\end{array}$ \\
\hline \multirow{2}{*}{5} & \multirow{2}{*}{ R2(Baghdad - Diyala) } & $\begin{array}{l}3 \text { hours and } 10 \\
\text { minutes }\end{array}$ & $\begin{array}{l}23-01- \\
2017\end{array}$ \\
\hline & & $\begin{array}{l}4 \text { hours and } 15 \\
\text { minutes }\end{array}$ & $\begin{array}{l}26-01- \\
2017\end{array}$ \\
\hline
\end{tabular}

\subsection{Site no.1 (expressway no.1- section R4)}

The Expressway No.1 is the major freeway in Iraq that extends from the Syrian and Jordanian borders to the Kuwaiti border, and connects various parts of Iraq. It is divided into two parts. The first part, which is about 583 $\mathrm{Km}$ long, leads from Baghdad to Safwan; the second part is about $615.9 \mathrm{Km}$ long and leads from Baghdad to the Syrian and Jordanian borders [7].

The study area is a part of section $\mathrm{R} / 4 \mathrm{~B}$ which starts at station $49+000 \mathrm{Km}$ located at the beginning of section $\mathrm{R} / 4 \mathrm{~B}$ at AL-Latifiya city. The pavement section has six lanes; three in each direction, with a standing lane, each direction is separated by an island as indicated by Figure 2 and Figure 3.

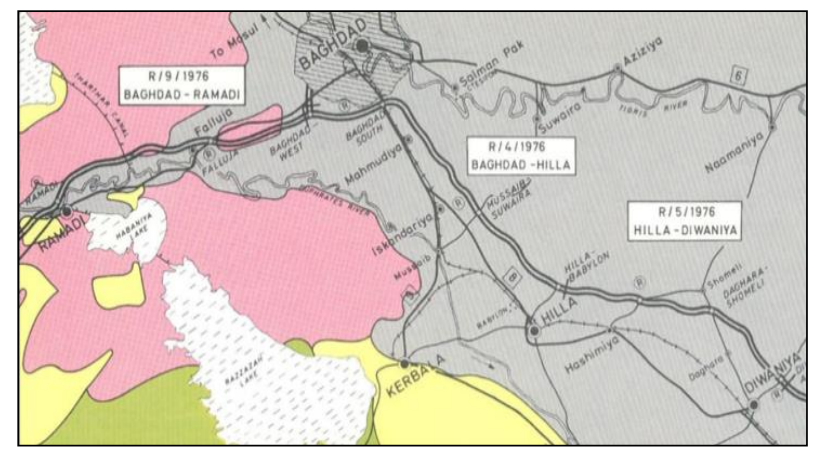

Fig. 2. Location of Section R4/Expressway No.1 in Iraq.

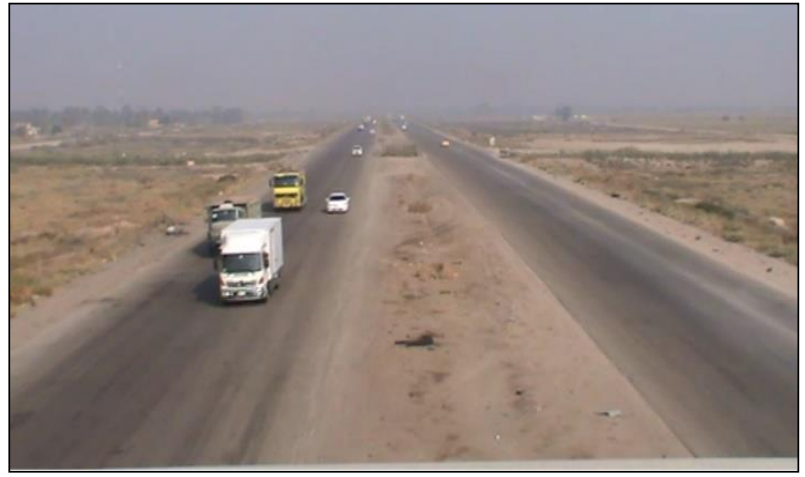

Fig. 3. Layout of Site No.1.

The most important thing observed on this road is the absence of pavement marking along the road. This mainly makes the task more difficult to track the changing vehicle from one lane to another. Moreover, the absence of these markings makes the drivers to be unstable or restricted by the boundary of his/her lane. This finally leads to high number of LC than the case of roads with such markings.

\subsection{Site no.2 (Baghdad to Mahmoudiyah R8)}

This site represents the link between Baghdad and the southern provinces sites. It consists of the six-lanes; three lanes in each direction. The road surface contains markers and this helps in the analysis of the results as shown in Figure 4.

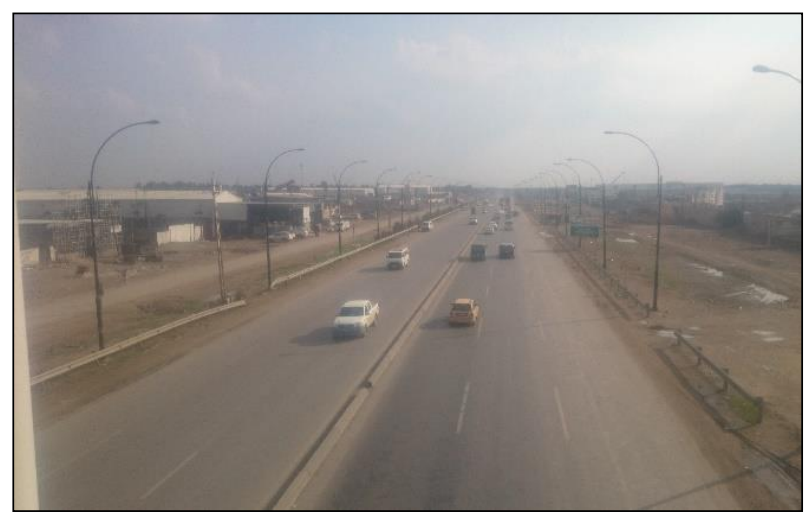

Fig. 4. Details of Site No.2.

\subsection{Site no.3 (Baghdad to Kut R6)}

This site belongs to a road linking the province of Baghdad and Kut, with three lanes in each direction and with a standard width of $12 \mathrm{ft}$ as demonstrated in Figure 5. This road starts from the borders of the new city of Baghdad until it reaches a checkpoint in the region of Al-Luj, where this region is within the boundaries of Wasit province. This road is important so that it is considered the main way to travel and exchange goods between Wasit province and Baghdad. 


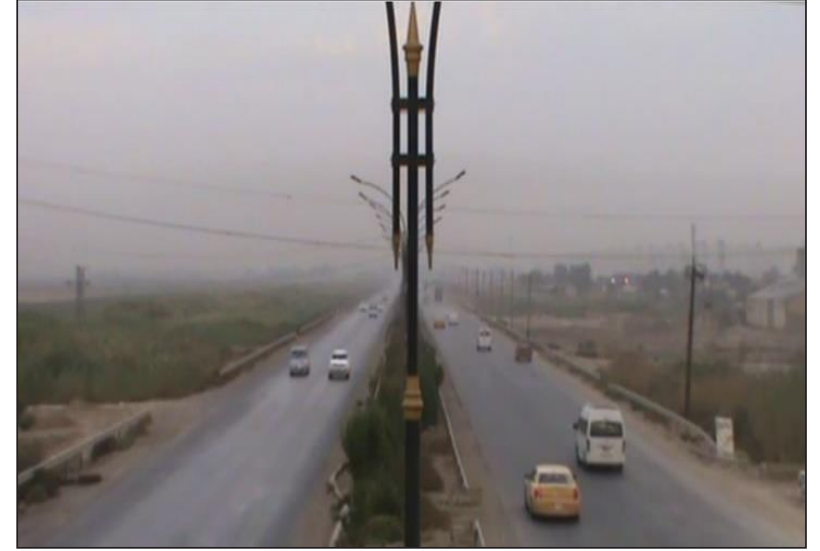

Fig. 5. Geometric design of Site No. 3.

\subsection{Site no.4 (Baghdad to Kut R6)}

This site belongs to a road linking the province of Baghdad and Kut, a two-lane in each direction and with the standard width of lane 12ft as shown in Figure 6. This road begins after the checkpoint of Wasit province towards Baghdad governorate until the checkpoint reaches the region of the Al-Luj, and then turns into a section with three lanes. It is used by many of the neighboring population in their movement and is also a link between the southern provinces (ie Basra, Amarah and Dhi Qar) With Baghdad, where many large truck drivers use it to transport goods coming from Basra or from border crossings with Iran .

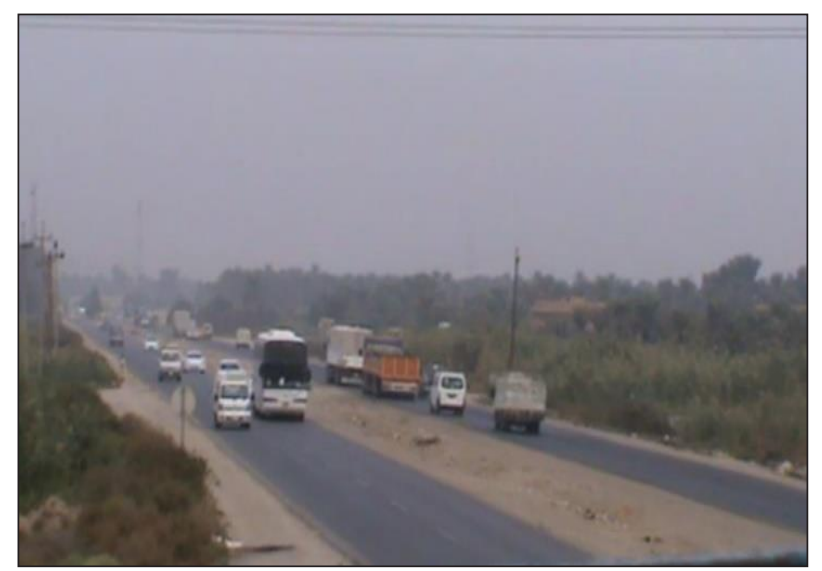

Fig. 6. Details of geometric design for Site No.4.

\subsection{Site no.5 (Baghdad to Diyala R2)}

This is the road linking the province of Baghdad and Diyala province, a two lanes in each direction with a width measuring $12 \mathrm{ft}$ as demonstrated by Figure 7 . It is one of the important roads linking the provinces of the center and south, northern governorates.

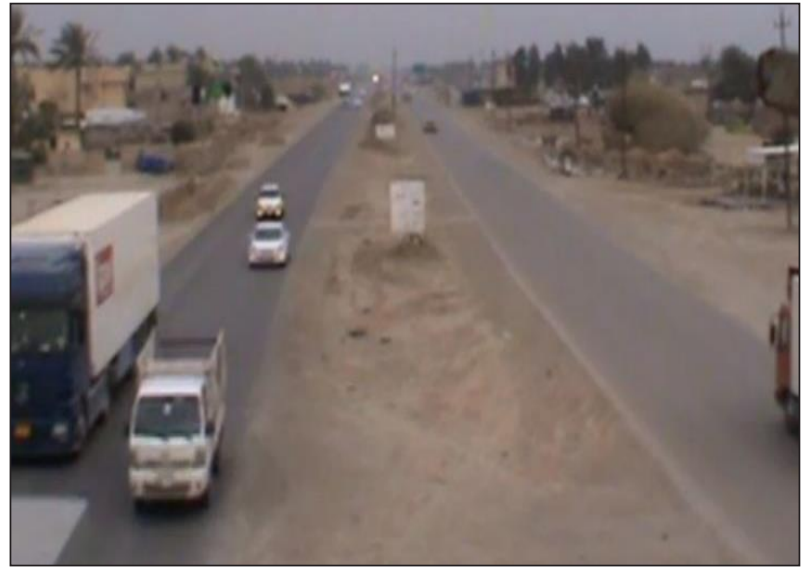

Fig. 7. Layout of Site No.5 (Source: from video record).

\section{Data analysis}

Having reported the collection data from the different sites mentioned above, the analysis of these data has taken a lot of efforts to classify the vehicles. Moreover, checking the lane changing for each vehicle is so difficult because the vehicle should be tracked from the time of entering the boundary of determined section by two lines drawn on the screen of the laptop to the time of exiting. Tracking each vehicle is consuming time.

Figure 8 shows the number of LC with the variation of flow from about $300 \mathrm{veh} / \mathrm{hr}$ to about $2000 \mathrm{veh} / \mathrm{hr}$. The maximum number of LC is about 1150 . It was observed from field data that the overtaking from right which is considered as violation is predominated. However, the number of LC for such section is lower than similar section.

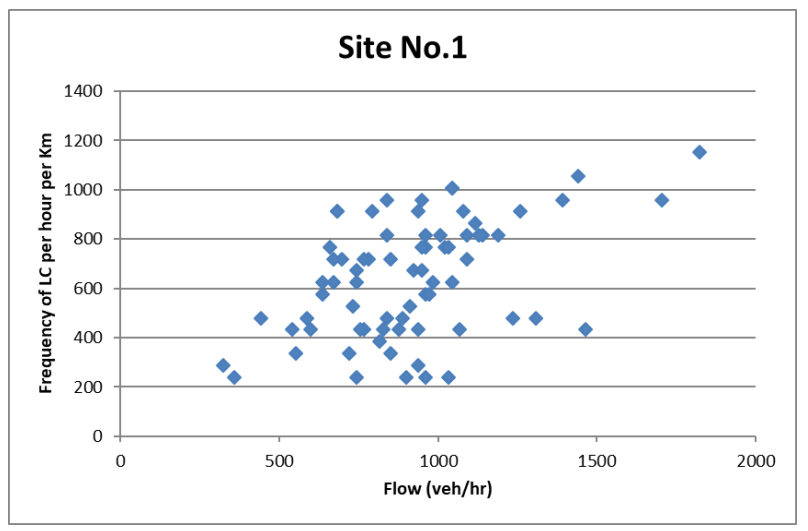

Fig. 8. Frequency of LC with flow Site No.1.

The lane utilization (LU) is another factor which represents driver behavior. Figure 9 indicates that drivers prefer to be in the second lane under low to moderate flow. Whereas, the third lane represents the second option for drivers. The first lane has still the lowest flow of vehicles. The maximum value for the LU for the first lane does not exceed 20 at any flow. This could be attributed to the high distresses spreading in this lane such as rutting and other types of damages resulting from heavy vehicles and absence of maintenance. 
The percentage of HGV, as indicated in Figure 10, is higher comparing with other normal lanes. This percentage is about $40 \%$ under moderate flow. This high value could be the cause that interpreting the high value of LC comparing with other countries such as the UK.

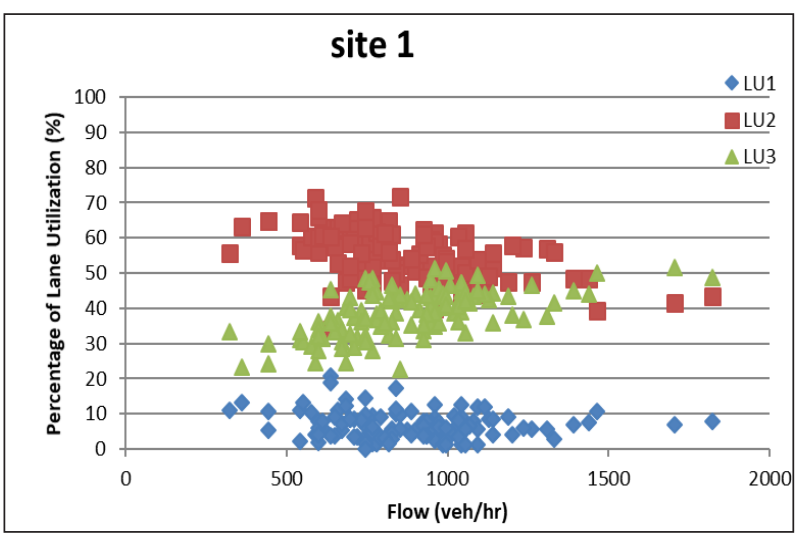

Fig. 9. Percentage of LU with flow.

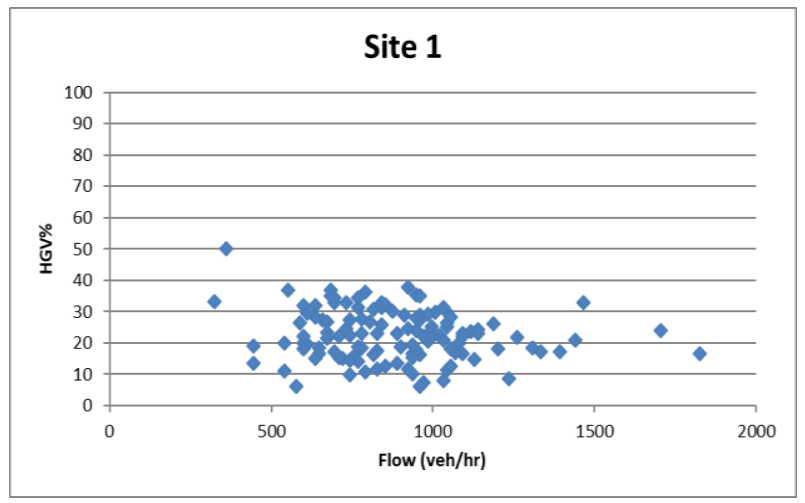

Fig. 10. Percentage of HGV with flow.

Figure 11 shows how the drivers are distributed among the three lane normal section. Again as observed in the Site No.1, the drivers focus at the second lane up to moderate flow then the high percentage of vehicles concentrates in the third lane. This behavior is approximately similar to the behavior observed at the Site No.3 (see Figure 14) and the UK sites as indicated in Figure 1.

At the Site No.2 it was observed that the frequency of the LC, as indicated in Figure 12, is similar in its behavior to that reported by Al-Jameel [6] in the UK (there is an increase up to around $3000 \mathrm{veh} / \mathrm{hr}$ then there is a reduction in the frequency of LC towards the capacity. However, the maximum value is beyond that observed in the UK. Another factor has an effect on this behavior is the percentage of $\mathrm{HGV}$ as indicated in Figure 13.

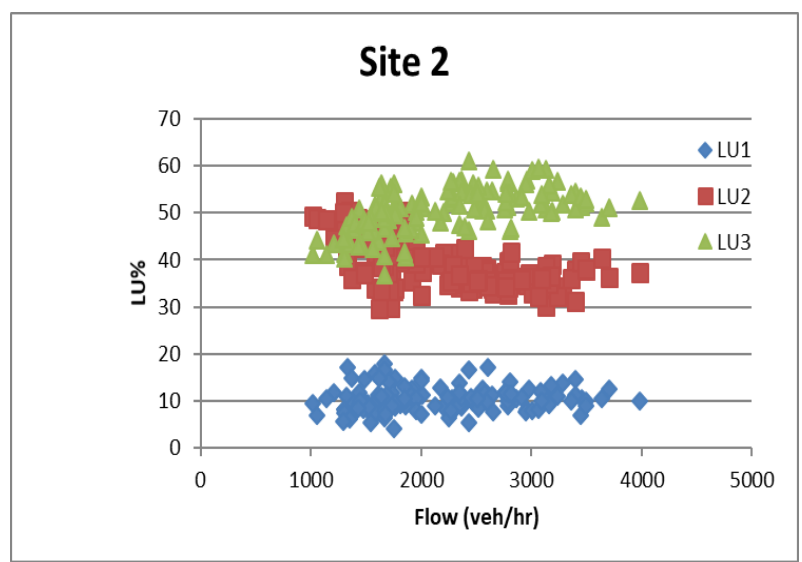

Fig. 11. Percentage of LU with flow.

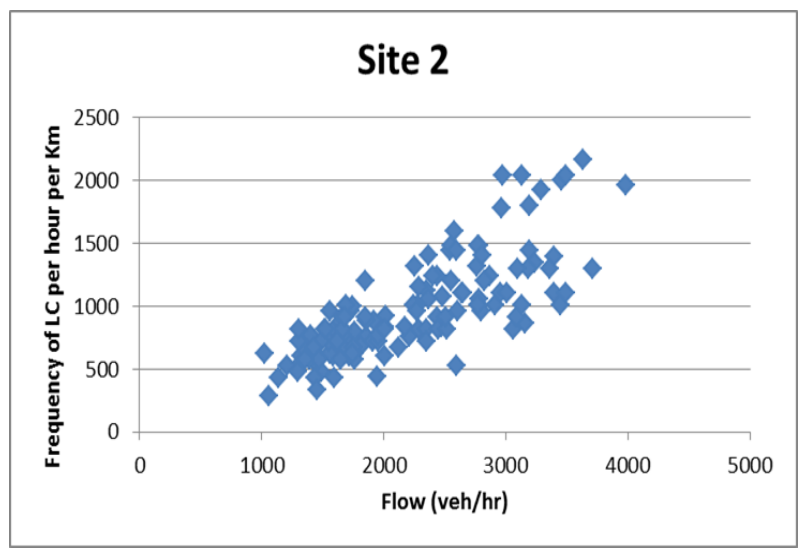

Fig. 12. Frequency of LC with flow Site 2.

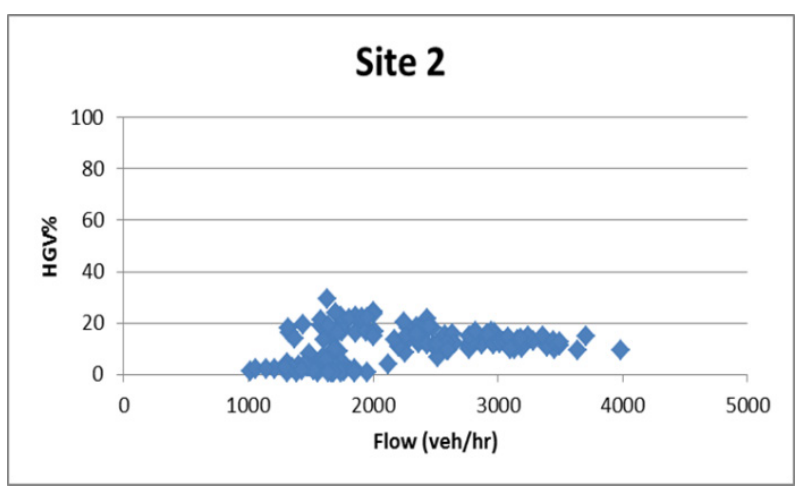

Fig. 13. Percentage of HGV with flow.

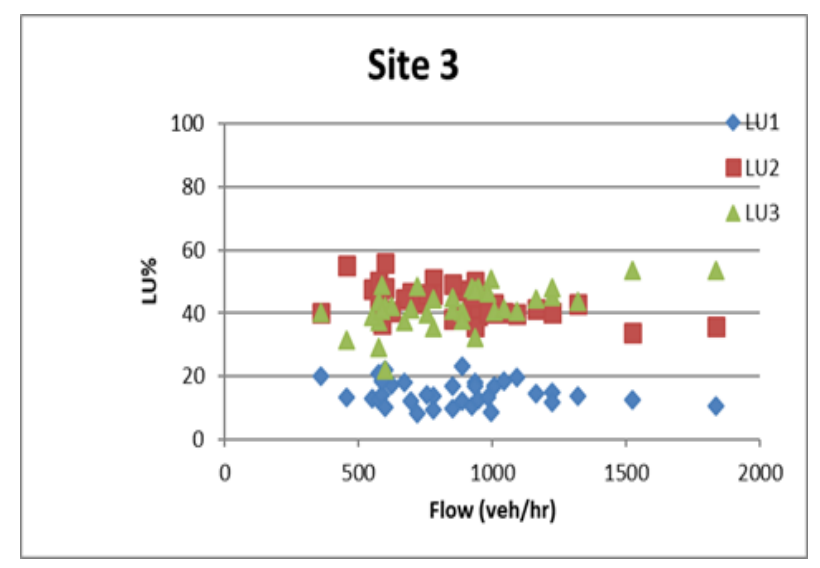

Fig. 14. Percentage of LU with flow Site 3. 
The fourth and fifth sites are approximately different from the previous sites in terms of number of lane. They are two lane sections. The main factor has been dissected is the LU. It was observed that the drivers prefer to be in the second lane at different flow rate as demonstrated in Figures 15 and 16.

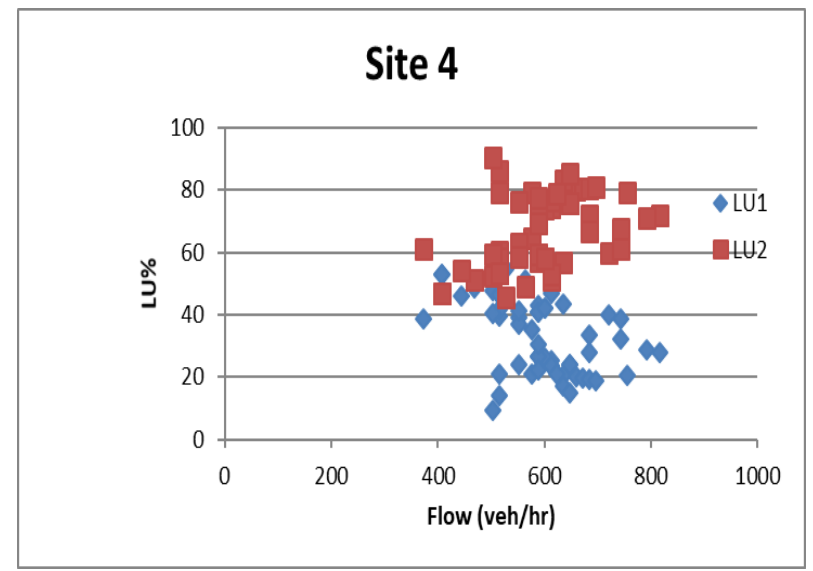

Fig. 15. Percentage of LU with flow Site 4.

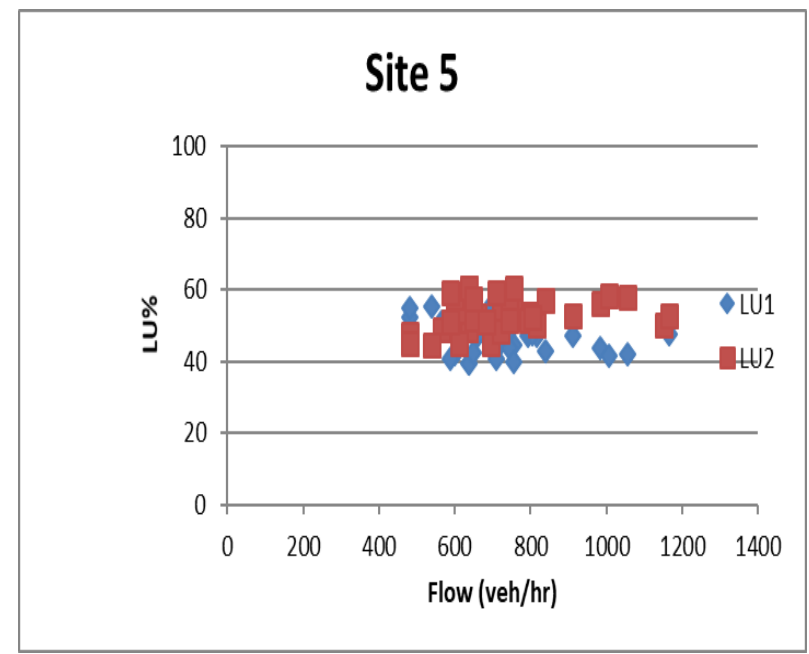

Fig. 16. Percentage of LU with flow Site 5.

From the above data for all sites, it was found there is an urgent need for installing loop detector in rural roads. Firstly, to obtain accurate data for some traffic characteristics such as flow, speed, headway and occupancy. Secondly, to get enough amount of data required for $\mathrm{LU}$ and other characteristics.

In the light of above, these data could be used for calibration and validation of simulation models in terms of the LC behavior for both two and three lane sections. Besides, the LU is another calibrated and validated factor which has an important factor to correct the behavior of simulated model.

\section{Conclusions and recommendations}

The main conclusions extracted from this study could be summarized as:

- The frequency of lane changes in Iraq is higher than that for other countries such the UK. This could be attributed to illegal LC (from left lane).

- The LU for the three lane section indicates that the passing lane does not use for overtaking the faster vehicles but used by all vehicles. On the other hand, most vehicles avoid to use the first lane because of high distresses.

- The absence of pavement markings does not only affect the FLC but also affects the traffic operations and safety.

- There is a need for correcting the driver behavior in terms of overtaking in illegal way and putting loop detector to get more accurate picture of driver behavior.

\section{References}

1. H. Al-Jameel, Developing a simulation model to evaluate the capacity of weaving sections, University of Salford (2012).

2. J.Wang, A merging model for motorway traffic The University of Leeds (2006).

3. S. Lee, Development of a Three Dimensional Lane Change Model, University of Illinois at UrbanaChampaign (2008).

4. H. Al-Jameel, Kufa journal of Engineering,5(2) (2014).

5. H. Al-Jameel, Journal of Babylon,. vol.25(1), Iraq (2017).

6. H. Al-Jameel, The $2^{\text {nd }}$ International Conference on Buildings, Construction and Environmental Engineering BCEE2, 17-18 October, Beirut, Lebanon., (2015).

7. M. Hamid, Backcalculation of Flexible Pavement Moduli Based on Genetic Algorithm Technique. Highway \& Transportation Engineering Department, Al-Mustansiriya University (2012). 